\title{
The Evolution of Microstructure, Mechanical Properties and Fracture Behavior with Increasing Lanthanum Content in AZ91 Alloy
}

\author{
Di Tie $^{1}$, Yi Jiang ${ }^{1}$, Renguo Guan ${ }^{1}$, Minfang Chen ${ }^{2}$, Jufu Jiang ${ }^{3}$, Fei Gao ${ }^{1}$, Xiaopeng Lu $^{1}$ \\ and Zhanyong Zhao ${ }^{4, *(D)}$ \\ 1 Key Laboratory of Lightweight Structural Materials Liaoning Province, School of Materials Science and \\ Engineering, Northeastern University, Shenyang 110819, China; tie-di@hotmail.com (D.T.); \\ jiangyi@mail.neu.edu.cn (Y.J.); guanrg@smm.neu.edu.cn (R.G.); gaof@mail.neu.edu.cn (F.G.); \\ luxiaopeng@mail.neu.edu.cn (X.L.) \\ 2 School of Materials Science and Engineering, Tianjin University of Technology, Tianjin 300384, China; \\ mfchentj@126.com \\ 3 School of Materials Science and Engineering, Harbin Institute of Technology, Harbin 150001, China; \\ jiangjufu@hit.edu.cn \\ 4 School of Materials Science and Engineering, North University of China, Taiyuan 030051, China \\ * Correspondence: syuzzy@126.com; Tel.: +86-351-3922012
}

Received: 23 August 2020; Accepted: 14 September 2020; Published: 17 September 2020

\begin{abstract}
AZ91 alloy is a widely applied commercial magnesium alloy due to its good castability, balanced mechanical properties and acceptable price, and lanthanum alloying has been proven to be one of the most effective methods to further improve its mechanical properties. Therefore, we reveal the evolution of microstructure, mechanical properties and fracture behavior with increasing lanthanum content in AZ91 alloy in this study. The magnesium matrix was significantly refined by lanthanum content, and this effect became more evident with increasing addition of lanthanum. The presence of $\mathrm{Al}_{3} \mathrm{La}$ precipitates significantly reduced the grain mobility and suppressed the formation of $\mathrm{Mg}_{17} \mathrm{Al}_{12}$ discontinuous precipitates along the grain boundaries. The rheo-cast alloys exhibited improved and balanced tensile strength and ductility after aging treatment. The fracture type of AZ91-La alloys could be classified as ductile fracture due to the presence of less quasi-cleavage planes and more dimples with a mixture of tear ridges and micropores. Due to the fully refined microstructure and the balanced mechanical properties, the AZ91-1.0La (mass\%) alloy presented the greatest potential for industrial applications among the three studied AZ91-La alloys.
\end{abstract}

Keywords: AZ91 alloy; magnesium alloy; lanthanum; mechanical properties; fracture behavior

\section{Introduction}

Magnesium alloys have been widely applied in automotive, aerospace and biomedical industries, which can be attributed their low density, high specific strength and good castability [1-3]. The application of magnesium alloys also appropriately meets the demand for lightweight heat dissipation materials including electronic components, vehicle parts and heat sink components, which has increased in recent years [4-6]. Among the various cast magnesium alloys, AZ91 alloy became one of the most widely used cast magnesium alloys due to its outstanding castability and aging hardenability $[7,8]$. Despite these advantages, AZ91 alloy still has some other limitations, including low ductility, insufficient formability, low Young's modulus and poor corrosion resistance, which narrow its industrial applications $[9,10]$. Thus, the improvement of AZ91 alloy's comprehensive performance, especially its mechanical properties, has become a research focus in recent years. 
The continuous network morphology of the $\mathrm{Mg}_{17} \mathrm{Al}_{12}$ phases along the grain boundaries in $\mathrm{AZ} 91$ alloy matrix was the main reason for its lower ductility. Many studies have been conducted in the past few years to improve the microstructural stability of AZ91 by deformation, heat treatment and alloying. Among the various methods, alloying was proven to be one of the most effective routes to adjust the microstructure and improve the mechanical properties of AZ91 alloy. Sn, Sb, Bi, etc. are usually introduced in the alloying of AZ alloys to improve their mechanical performance [11-13]. Previous results indicated that rare earth elements were relatively more effective in optimizing AZ91's mechanical performance than other elements [8,14]. In AZ91 alloy matrix, rare earth elements (RE) could form Al-RE intermetallics, which increase its ultimate strength and its creep resistance $[15,16]$. It is well known that lanthanum is a low-cost RE element, which ensures its potential in large scale industrial applications $[17,18]$. Moreover, the thermal conductivity of magnesium alloys will not be greatly influenced by the addition of lanthanum content due to its low solid solubility in the magnesium matrix, which is crucial for heat sink products $[6,19]$.

Another advantage of lanthanum alloying is that Al-La intermetallics could be formed in the alloy matrix, which maintain the high thermal conductivity of the alloys [20]. After aging treatment, both the Al-La intermetallics and the $\mathrm{Mg}_{17} \mathrm{Al}_{12}$ phases further strengthened the alloy matrix by precipitation. $\mathrm{Mg}_{17} \mathrm{Al}_{12}$ continuous precipitates (CPs) with plate-shaped morphology and $\mathrm{Mg}_{17} \mathrm{Al}_{12}$ discontinuous precipitates (DPs) with lamellar morphology were formed as partially divorced precipitates during the aging treatment $[21,22]$. Although the CPs and the DPs both have a bcc structure, they play distinct roles in the improvement of mechanical properties [12,22]. Jain et al. reported that both CPs and DPs could effectively conduct precipitation strengthening at different temperatures [23]. Stanford et al. studied the effect of CPs on the tensile behavior of AZ91 alloy and found that that the age hardening was conducted by both twinning deformation and the precipitation of CPs [24]. We also revealed the strengthening mechanism of the CPs and the DPs in AZ91-Sn alloys in our previous studies [12]. However, there is still a lack of understanding regarding the precipitate distribution and its influence on the mechanical properties of AZ91 alloy with lanthanum alloying. Therefore, we carried out this study to investigate the evolution of microstructure, mechanical properties and fracture behavior with increasing lanthanum content in AZ91 alloy.

\section{Materials and Methods}

AZ91 alloy with 0.5 mass $\%, 1.0$ mass $\%$ and 1.5 mass $\%$ lanthanum addition (nominal chemical composition) were investigated as the experimental materials, which were designated AZ91-0.5La, AZ91-1.0La and AZ91-1.5La, respectively. The AZ91 alloy (AZ91D, Zhongtai, China) and Mg-La master alloy (10 mass\%, Boyue, China) were weighed, mixed and melted under protective atmosphere $\left(\mathrm{Ar}+1.5 \mathrm{vol} . \% \mathrm{SF}_{6}\right)$ at $690^{\circ} \mathrm{C}$ and processed into semi-solid slurry using a rheo-treatment machine [12]. The melt was then held at $685^{\circ} \mathrm{C}$ for $30 \mathrm{~min}$ in a steel crucible, and the solidification process was performed by immersing the crucible in cooling water. The chemical compositions of the AZ91-La alloys were analyzed by an inductively coupled plasma-atomic emission spectroscope (ICP-OES, ICP Pro, Thermo Fisher, MA, USA). The rheo-cast alloys were then processed sequentially by solid solution treatment and aging treatment. The solution treatment was performed at $380^{\circ} \mathrm{C}$ for $8 \mathrm{~h}$ with water quenching, and the aging treatment was conducted at $180^{\circ} \mathrm{C}$ for $48 \mathrm{~h}$ under protective atmosphere.

Optical microscopy (OM, LV150N, Nikon, Japan) was applied to observe the microstructure evolution of the AZ91 alloy with different amounts of lanthanum content, and a scanning electron microscope (SEM, JCM-5000, Nikon, Kyoto, Japan) fitted with an energy dispersive X-ray spectrometer (EDS, Ametek, San Diego, CA, USA) was used to identify the distribution and composition of the precipitates. The phase identification was further performed by using an X-ray diffractioner (XRD, Bruker, Madison, WI, USA) with $\mathrm{Cu} \mathrm{K} \alpha$ radiation at $40 \mathrm{kV}$.

The tensile tests were carried out according to ASTM standard, and the dimensions of the specimens are depicted in Figure 1. Specimens were tested by a tension tester (CMT5305; MST, Jinan, China) with a stretching rate of $3.0 \mathrm{~mm} \cdot \mathrm{min}^{-1}$. An automatic extensometer (Sinotest, Changchun, 
China) was employed to record the strain values. The measurements were performed in ten duplicates, and the results are presented as mean value \pm standard deviation (SD). One-way analysis of variance test was applied for comparisons of the means between different groups, with confidence intervals of $95.0 \%\left(^{*}, p<0.05\right)$ and $\left.99.0 \%{ }^{* *}, p<0.01\right)$, whilst NS stands for no significant difference. The fracture morphology and mechanism were analyzed by means of SEM (JCM-5000, Nikon, Kyoto, Japan) fitted with an energy dispersive $X$-ray spectrometer (Ametek, San Diego, CA, USA).

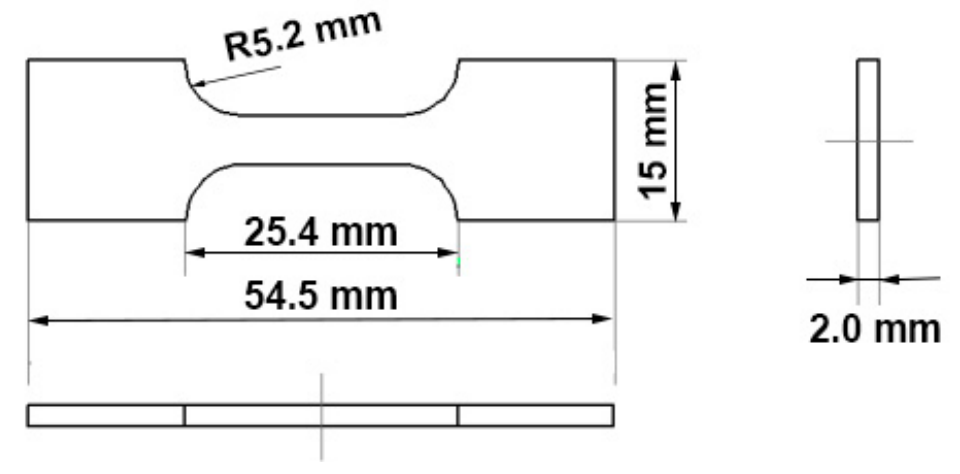

Figure 1. The scheme and dimensions of the samples for tensile tests.

\section{Results and Discussion}

\subsection{Microstructure Evolution}

The experimentally measured chemical compositions of AZ91-La alloys are summarized in Table 1. The optical micrographs of the AZ91 alloy and the AZ91-La alloys are shown in Figure 2. The magnesium matrix was significantly refined by lanthanum content, and this effect became more evident with increasing amounts of added lanthanum. The second phase particles mostly distributed along grain boundaries, whose sizes were significantly homogenized and reduced with increasing amounts of lanthanum as well. With 0.5 mass \% addition of lanthanum, the grain size was decreased from $160.2 \pm 15.1 \mu \mathrm{m}$ in AZ91 alloy to $87.0 \pm 7.5 \mu \mathrm{m}$, while a dendritic structure still existed in the matrix. When the content of lanthanum increased to 1.0 mass $\%$ and 1.5 mass $\%$, the average grain size was reduced to $65.0 \pm 4.5 \mu \mathrm{m}$ and $60.3 \pm 6.2 \mu \mathrm{m}$, respectively.

Table 1. The experimentally measured chemical composition (mass fraction) of AZ91-La alloys.

\begin{tabular}{cccccccc}
\hline Alloy & Mg & Al & Zn & La & Mn & Si & Cu \\
\hline AZ91 & Balance & 9.23 & 0.86 & 0 & 0.21 & 0.03 & 0.01 \\
AZ91-0.5La & Balance & 9.19 & 0.86 & 0.48 & 0.21 & 0.03 & 0.01 \\
AZ91-1.0La & Balance & 9.15 & 0.84 & 0.97 & 0.20 & 0.02 & 0.01 \\
AZ91-1.5La & Balance & 9.10 & 0.84 & 1.46 & 0.20 & 0.03 & 0.01 \\
\hline
\end{tabular}

In the SEM micrographs of the AZ91 alloy and the AZ91-La alloys (Figure 3), the precipitates manifested two different morphologies after aging treatment. Apart from the coarse, fully divorced precipitates, continuous precipitates (CPs) with plate-shaped morphology and discontinuous precipitates (DPs) with lamellar morphology were both observed as partially divorced precipitates. Similar morphologies were also observed in previous studies on AZ91 alloys [10,12]. According to the EDS results, both the CPs and the DPs were composed by eutectic $\mathrm{Mg}_{17} \mathrm{Al}_{12}$, while the isolated needle-like precipitates were identified as $\mathrm{Al}_{3} \mathrm{La}$. The optical and $\mathrm{SEM}$ micrographs demonstrated that the addition of lanthanum content to AZ91 alloy could simultaneously refine the magnesium matrix and the $\mathrm{Mg}_{17} \mathrm{Al}_{12}$ precipitates. The average size of the fully divorced precipitates was decreased from $32.3 \mu \mathrm{m}$ in AZ91 alloy to $7.4 \mu \mathrm{m}$ in AZ91-1.5La alloy. Due to the precipitation of $\mathrm{Al}_{3} \mathrm{La}$, the formation of DPs and CPs was suppressed [25]. Grain boundary mobility is considered the primary determinant 
in the precipitation of DPs [26]. In our investigation, the grain boundary density was increased with increasing addition of lanthanum content due to its grain refinement effect [17]. Moreover, the presence of $\mathrm{Al}_{3} \mathrm{La}$ particles also reduced the grain mobility. As a result, the DPs could hardly precipitate along the grain boundaries.
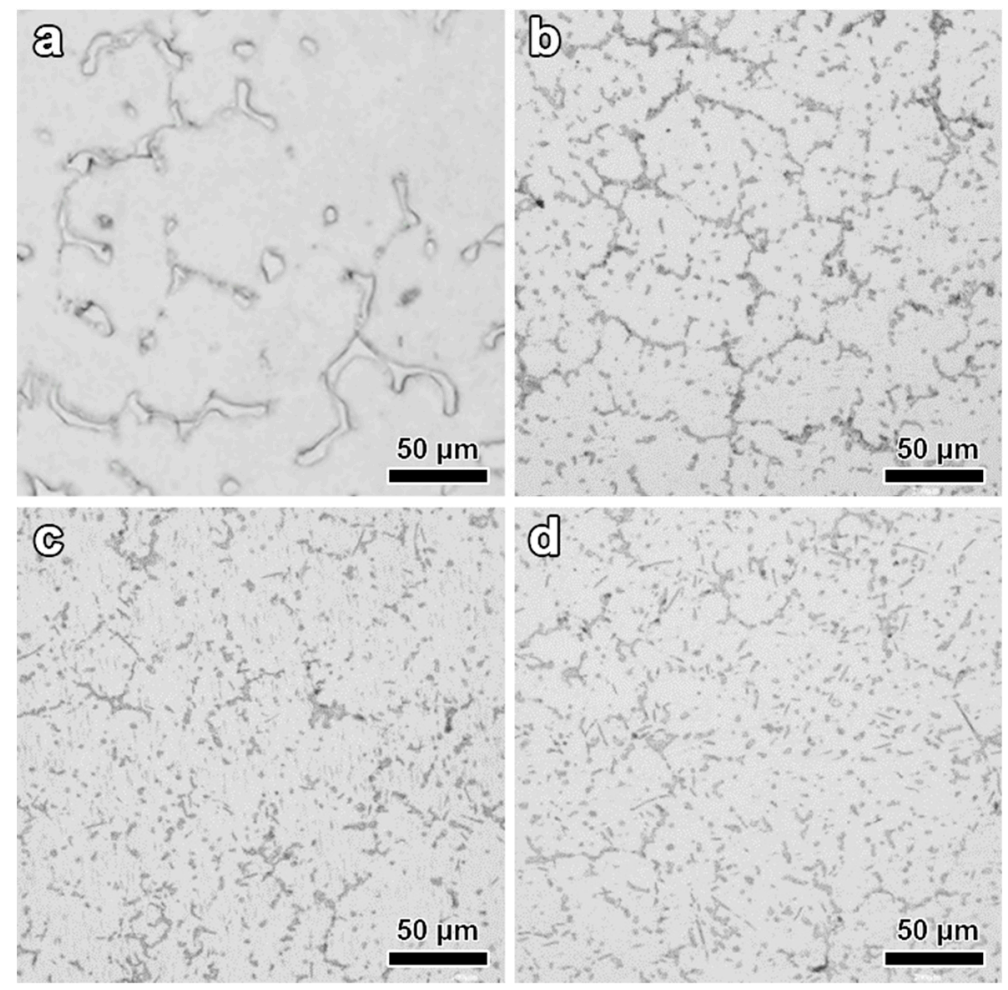

Figure 2. The optical micrographs of (a) AZ91, (b) AZ91-0.5La, (c) AZ91-1.0La and (d) AZ91-1.5La.

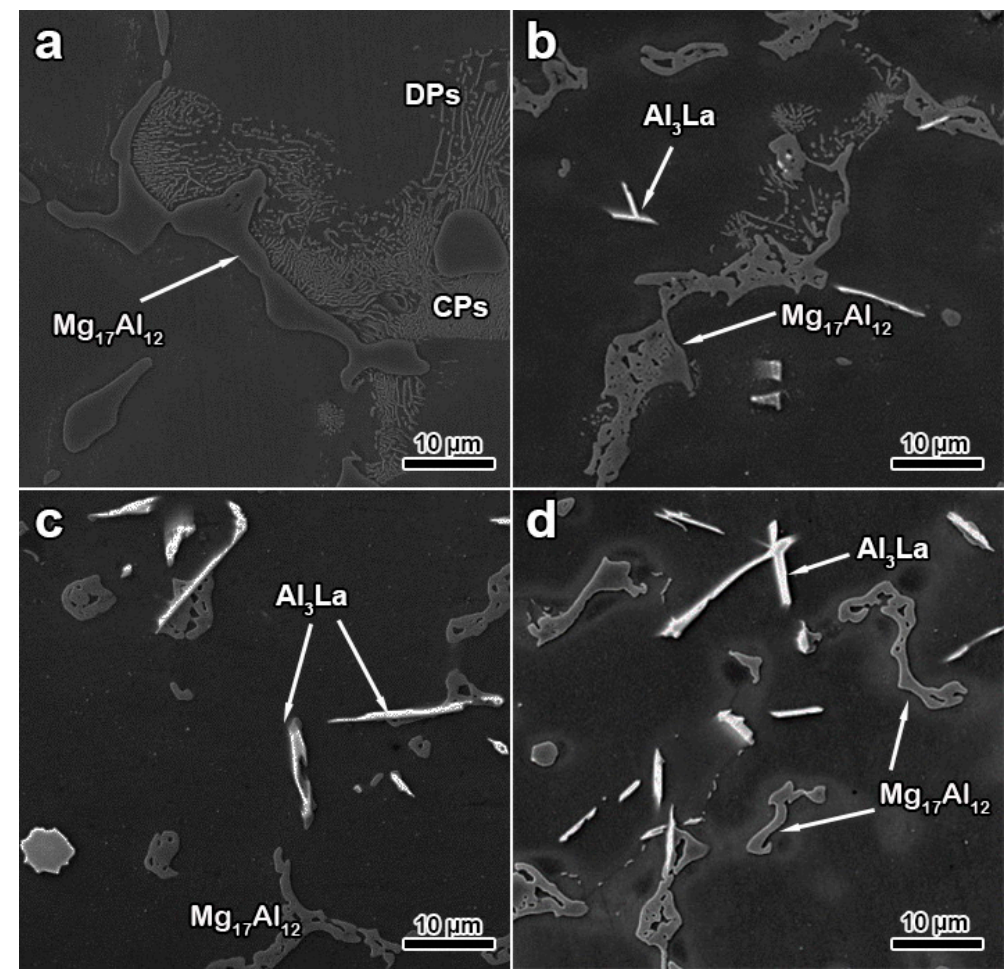

Figure 3. The SEM micrographs of (a) AZ91, (b) AZ91-0.5La, (c) AZ91-1.0La and (d) AZ91-1.5La. 
The XRD analysis results of the alloys are shown in Figure 4. $\alpha$-Mg and $\mathrm{Mg}_{17} \mathrm{Al}_{12}$ as the primary species were identified in all the alloys, and the $\mathrm{Al}_{3} \mathrm{La}$ phase was analyzed in all three AZ91-La alloys [25]. The intensity of the signal peak was in direct proportion to the content of lanthanum in the alloy. The TEM investigation (Figure 5) further confirmed the phase identification results from the XRD analysis. It is notable that, besides the coarse $\mathrm{Al}_{3} \mathrm{La}$ precipitates observed in Figure 3, smaller sized $\mathrm{Al}_{3} \mathrm{La}$ phases were also found in the $\mathrm{Mg}$ matrix. Figure 5 also depicts the indexed [100] zone of bcc $\mathrm{Al}_{3} \mathrm{La}$ [18]. According to the microstructure observation and phase identification results, it can be concluded that lanthanum content existed in two forms in the alloy matrix, the isolated needle-like precipitates with an average size of $13.4 \mu \mathrm{m}$ and the dispersed precipitates in micro scale.

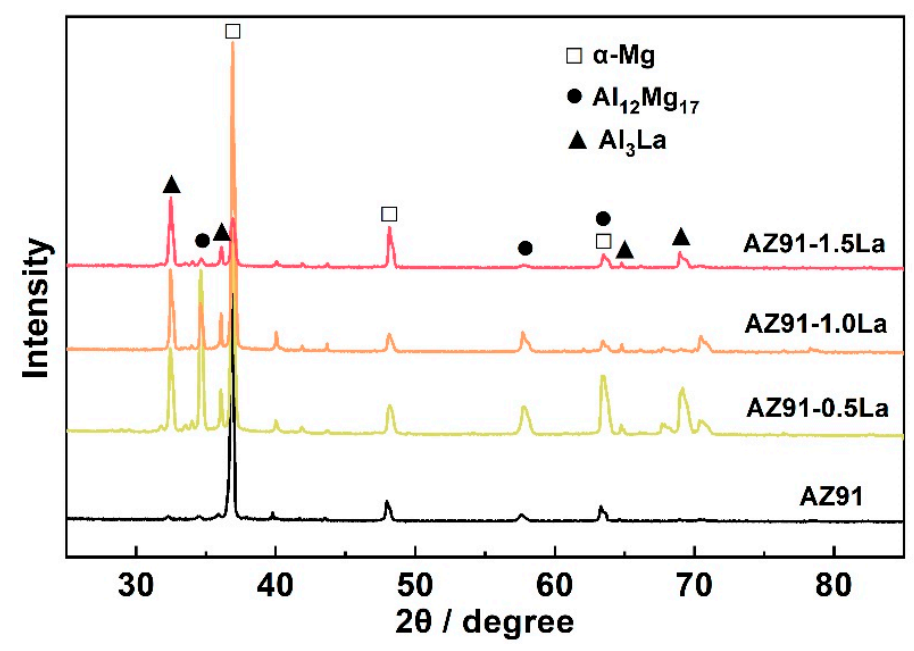

Figure 4. The XRD analysis results of AZ91 and AZ91-La alloys.

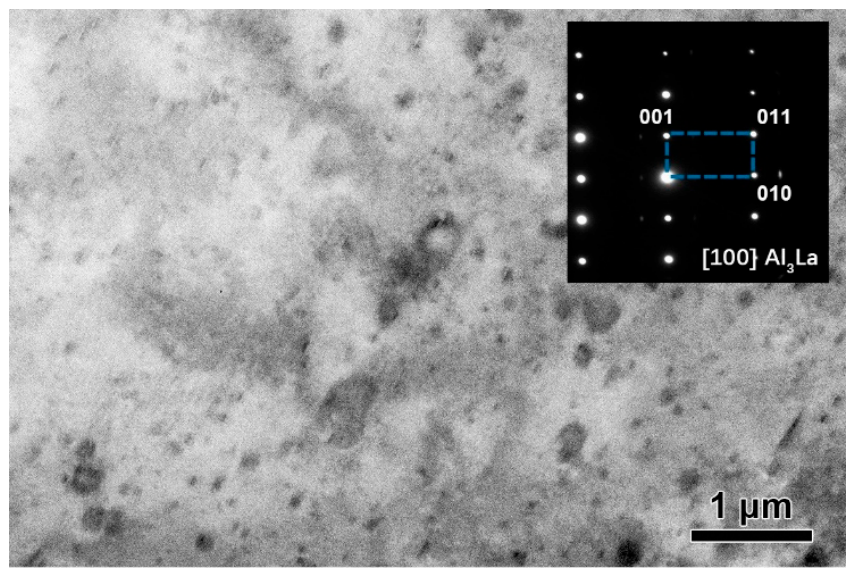

Figure 5. The TEM microstructure of AZ91-1.5La alloy and the selected area electron diffraction pattern of the $\mathrm{Al}_{3} \mathrm{La}$ phase.

\subsection{Solidification Behavior and Mechanical Properties}

$\mathrm{Al}_{3} \mathrm{La}$ were mostly observed together with $\mathrm{Mg}_{17} \mathrm{Al}_{12}$ phases according to the microstructure results, indicating that the $\mathrm{Al}_{3} \mathrm{La}$ phase with higher melting point provided heterogeneous nucleation points for the $\mathrm{Mg}_{17} \mathrm{Al}_{12}$ phases. Therefore, more fully divorced $\mathrm{Mg}_{17} \mathrm{Al}_{12}$ precipitates formed while less partially divorced CPs and DPs generated with increasing lanthanum content. During the solidification process, the $\alpha$-Mg matrix first solidified. Then, La element enriched at the solid-liquid interfaces, and $\mathrm{Al}_{3} \mathrm{La}$ phases were formed with the decreasing temperature (Figure 6). Previous research has successfully identified the habit plane between $\mathrm{Mg}$ matrix and $\mathrm{Al}_{3} \mathrm{La}$ phases [18,25]. $\mathrm{Mg}_{17} \mathrm{Al}_{12}$ preferentially solidified along the habit plane $(\overline{2} 11 \overline{2})_{\mathrm{Mg}} / /(011)_{\mathrm{Al} L \mathrm{La}}$ and further grew via 
the heterogeneous nucleation points provided by $\mathrm{Al}_{3} \mathrm{La}$ phases. Figure 6 depicts the model of the solidification process of AZ91-La alloys.

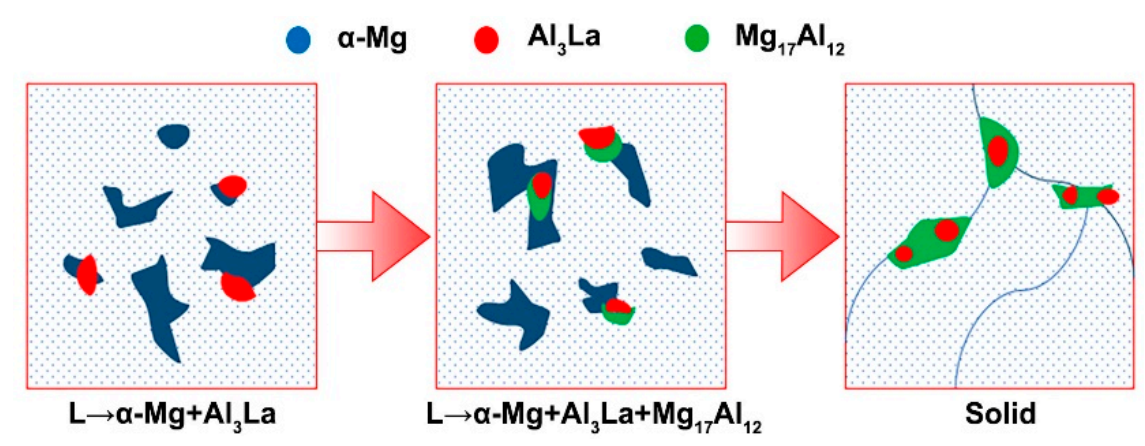

Figure 6. The schematic diagram of AZ91-La alloys' solidification process.

Figure 7 presents the grain size and the tensile properties of the aged AZ91 and AZ91-La alloy. With increasing lanthanum content, the average grain size decreased significantly (significance level $p<0.01$ ). Due to the grain refinement strengthening, both the tensile strength and the elongation showed pronounced increases. The AZ91-1.5La alloy gained ca. $54.8 \%$ increase in ultimate tensile strength compared to AZ91 alloy, from $225.5 \pm 6.7$ to $349.0 \pm 5.0 \mathrm{MPa}$. Due to the refined matrix, the high density grain boundaries bore more stress [9]. According to the stress-strain curve, both the yield strength and strain hardening exhibited positive stress dependence (Figure $7 \mathrm{~b}$ ). This effect became more evident with increasing lanthanum content. Furthermore, the precipitation of $\mathrm{Al}_{3} \mathrm{La}$ suppressed the formation of dendrites. As a result, the refined non-dendritic microstructure was observed in the AZ91-1.5La alloy (Figure 2), which led to the improved mechanical properties.
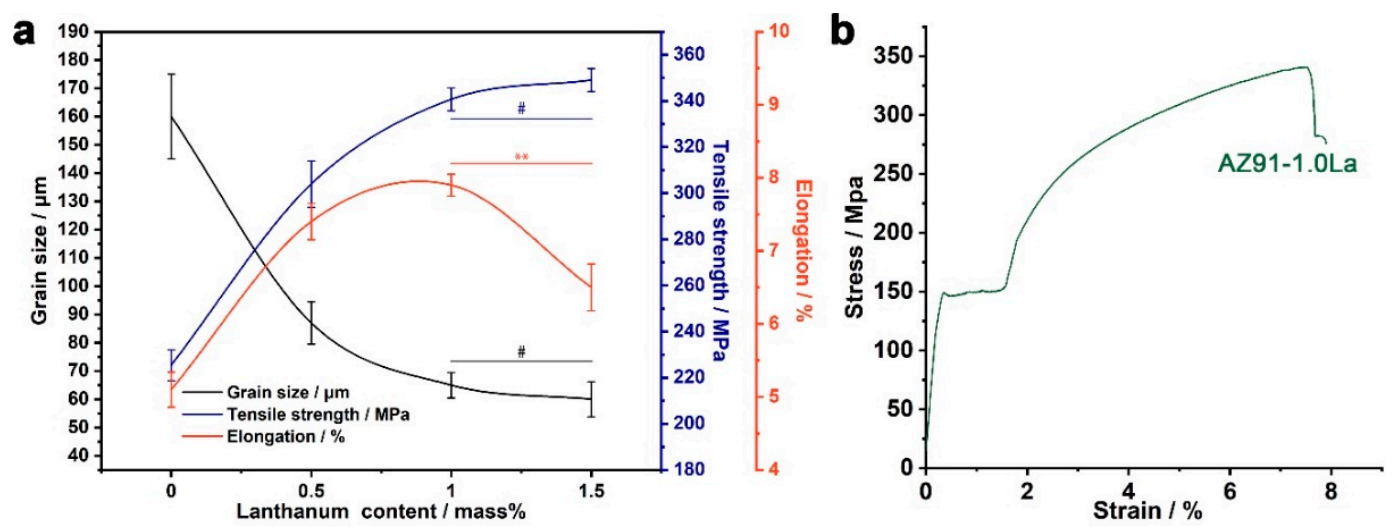

Figure 7. (a) The mechanical properties and average grain size of AZ91 alloy with different amounts of lanthanum content; (b) the stress-strain curve of AZ91-1.0La alloy; mean value \pm SD is presented.

It is evident that the AZ91-La alloys showed more significant work hardening effect than the AZ91 alloy. Previous studies proved that higher dislocation density and decreasing dynamic recovery of dislocations due to more solute atoms and fine precipitates could significantly enhance work hardening ability [27]. Our results confirmed that the high work hardening ability of AZ91-La alloys was primarily ascribed to the soluted La atoms in the alloy matrix [28]. Moreover, the high and balanced mechanical properties of the AZ91-La alloys were also attributed to the well-dispersed $\mathrm{Al}_{3} \mathrm{La}$ precipitates in micro scale, which increased the dislocation storage capability while suppressing the recovery of dislocations [8].

It is notable that 1.5 mass $\%$ lanthanum addition led to a significant decrease (significance level $p<0.01)$ in elongation while it did not significantly improve the tensile strength. The primary reason for this phenomenon was the increased amount of brittle intermetallics brought about by the high 
content of La (Figures 3 and 4). Although the intermetallics were also attributed to the improvement in tensile strength, the difference in hardness between the matrix and the intermetallics caused stress concentration at their interfaces [3]. Thus, the highest ultimate tensile strength but lower elongation were overserved in the AZ91-1.5La alloy [15].

\subsection{Fracture Behavior}

To study the fracture behavior of all the alloys, SEM fractographs of the tensile samples were analyzed (Figure 8). Twin boundary fracture was observed in all the tensile samples. As one of the main deformation forms of magnesium alloy, twinning deformation could suppress the dislocation motion by changing the favorable crack paths along the twin boundaries [29]. Due to the low deformation absorbed energy, the fracture morphology of AZ91 was primarily composed by river patterns and cleavage plans (Figure 8a). Given the high density cleavage steps and tearing edges which were observed in the river patterns, cleavage fracture was the primary fracture type in AZ91. With increasing lanthanum content, denser and deeper dimples were more often observed in the AZ91-La alloys, hinting that the alloys underwent ductile failure (Figure 8). Therefore, the fracture type of AZ91-La alloys could be classified as ductile fracture due to the presence of less quasi-cleavage planes and more dimples with a mixture of tear ridges and micropores (Figure 8) [30]. Due to the higher density dimples, shorter and more curved river patterns presented in the fracture morphology of AZ91-La alloys. The cleavage planes had an inclination angle of ca. $45^{\circ}$, with the tensile axis reflecting the maximum shear stress planes in tension and the typical cleavage length was ca. $15 \mu \mathrm{m}$, which was commonly observed in magnesium alloys after twinning deformation [31].
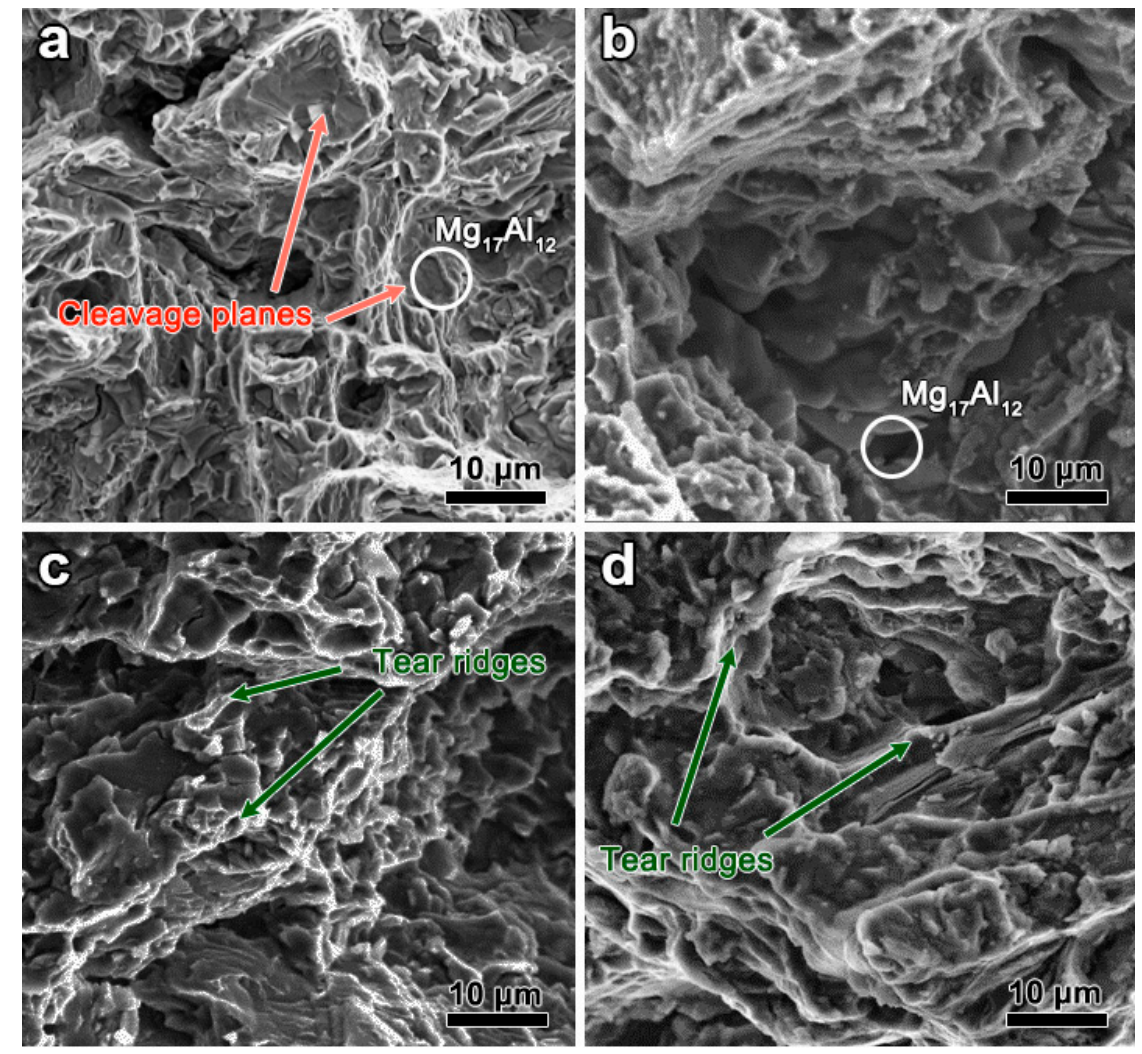

Figure 8. Representative SEM fracture morphology of (a) AZ91, (b) AZ91-0.5La, (c) AZ91-1.0La and (d) AZ91-1.5La.

Greater lanthanum addition led to a refined alloy matrix and therefore effectively hindered the generation and growth of cleavage cracks, due to which the AZ91-1.0La showed the least density of cleavage plane on the fracture surface and the highest elongation among the three AZ91-La alloys [32]. 
Apart from the normal ductile fracture morphology, we also found two kinds of fractured particles with bright contrast (Figure 8). The particles mostly segregated along the grain boundaries and were identified as $\mathrm{Zn}$ containing intermetallics $\left(\mathrm{Mg}_{4} \mathrm{Zn}_{7}\right.$ and $\left.\mathrm{MgZn}_{2}\right)$ by EDS analysis. The fracture morphology analysis hinted that fracture initiation sites mainly distributed around these intermetallics, which resulted in the transgranular ruptures and the decrease in elongation in AZ91-1.5La alloy.

It can be concluded from the SEM longitudinal section fractographs of the tensile samples that the interfaces between coarse $\mathrm{Mg}_{17} \mathrm{Al}_{12}$ DPs and the $\mathrm{Mg}$ matrix were the primary fracture initiation sites of the AZ91 alloy (Figure 9a). Further intergranular fractures were conducted by the growth and propagation along the grain boundaries [33]. Lanthanum addition improved the tensile strength of AZ91 alloy by refining the matrix and generating micro-sized precipitates with random orientations. As a result, more twins rather than cracks were found in the longitudinal sections of fractured AZ91-La alloys (Figure 9). Attributed to the refined matrix, the formation and propagation of cleavage cracks were effectively suppressed. As a result, microcracks formed around $\mathrm{Mg}_{17} \mathrm{Al}_{12} \mathrm{CPs}$ took the place of cleavage cracks around $\mathrm{Mg}_{17} \mathrm{Al}_{12}$ DPs and led to ductile fracture [34].
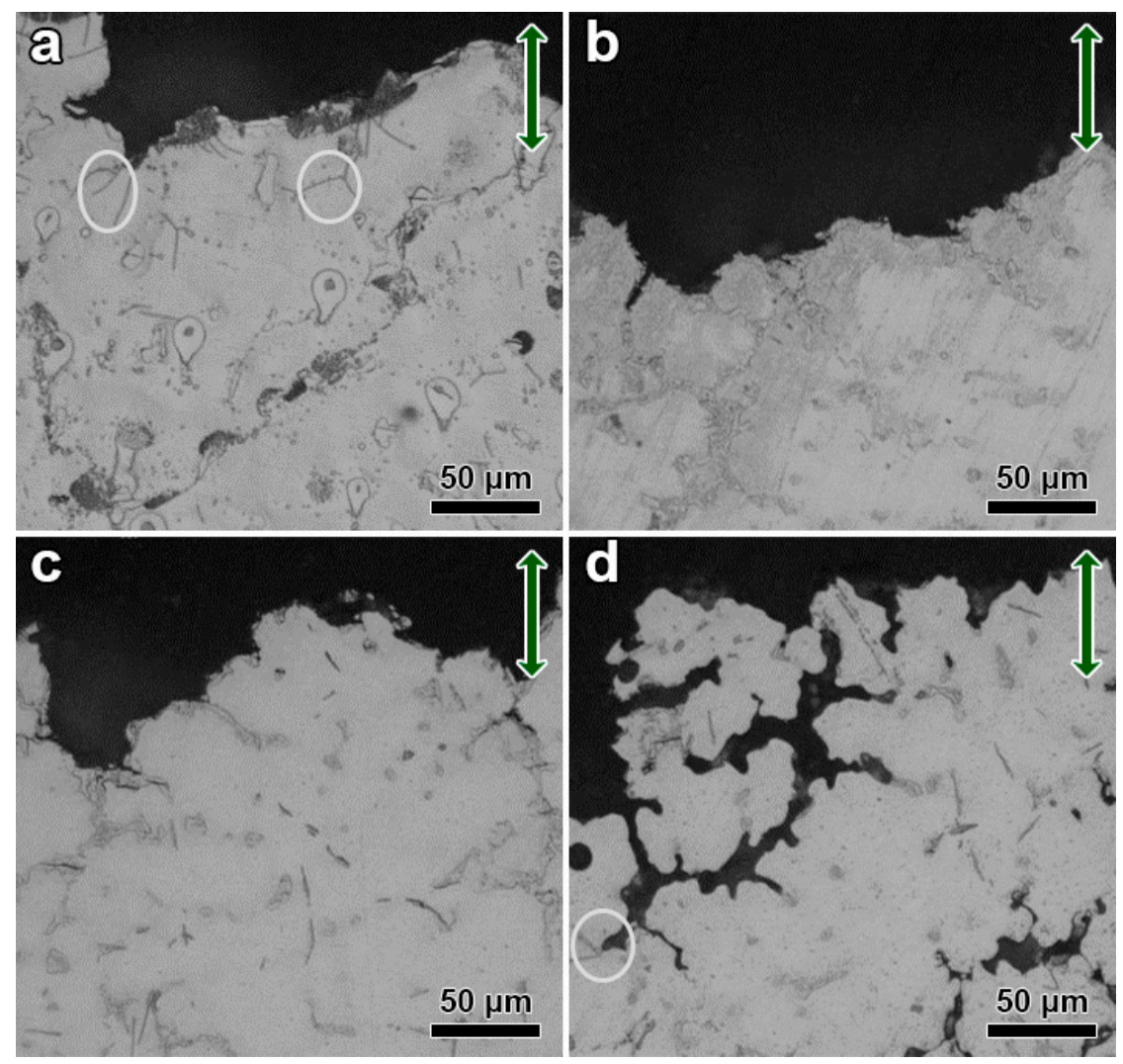

Figure 9. Tensile fracture morphology of longitudinal sections of (a) AZ91, (b) AZ91-0.5La, (c) AZ91-1.0La and (d) AZ91-1.5La; the load directions are marked by double arrowheads in each image, and the circled areas display the fracture initiation sites.

Another crucial effect brought about by more microcracks and twins induced by La alloying was the release of the stress concentration during the deformation process [9,12]. At the final tensile stage, the high tensile strength of the AZ91-La alloys was attributed to the specific orientations of the grains and the elevating density of the grain boundaries, while the activation of basal glide contributed to the improved ductility of the AZ91-La alloys [35]. Thus, the alloy withstood lager deformation and higher load with greater content of lanthanum. Our results regarding the fracture behavior demonstrated that the addition of lanthanum could simultaneously improve the tensile strength and the ductility of AZ91 alloy, and the improvement in ductility is especially crucial for the manufacture of thin-wall products. 
Among the three AZ91-La alloys, the AZ91-1.0La alloy presented the greatest potential for industrial applications due to the fully refined microstructure and the balanced mechanical properties.

\section{Conclusions}

(1) The magnesium matrix was significantly refined by lanthanum content, and this effect became more evident with increasing amounts of added lanthanum. When the content of lanthanum increased to $1.0 \mathrm{mass} \%$ and $1.5 \mathrm{mass} \%$, the average grain size was reduced to $65.0 \pm 4.5$ and $60.3 \pm 6.2 \mu \mathrm{m}$, respectively. The presence of $\mathrm{Al}_{3} \mathrm{La}$ precipitates significantly reduced the grain mobility and suppressed the formation of $\mathrm{Mg}_{17} \mathrm{Al}_{12}$ DPs along the grain boundaries.

(2) The precipitation of $\mathrm{Al}_{3} \mathrm{La}$ suppressed the formation of dendrites, so the refined non-dendritic microstructure was observed in the AZ91-La alloys. Due to the grain refinement strengthening, both the tensile strength and the elongation showed pronounced increases. The AZ91-1.5La alloy gained ca. $54.8 \%$ increase in ultimate tensile strength compared to AZ91 alloy, from 225.5 to $349.0 \mathrm{MPa}$, whilst the AZ91-10La alloy showed the highest elongation value.

(3) The fracture type of AZ91-La alloys could be classified as ductile fracture due to the presence of less quasi-cleavage planes and more dimples with a mixture of tear ridges and micropores. The fracture analysis results suggested that the interfaces between coarse $\mathrm{Mg}_{17} \mathrm{Al}_{12}$ DPs and the $\mathrm{Mg}$ matrix were the primary fracture initiation sites of the AZ91 alloy. Due to the fully refined microstructure and the balanced mechanical properties, the AZ91-1.0La alloy presented the greatest potential for industrial applications among the three AZ91-La alloys.

Author Contributions: Conceptualization, D.T.; methodology, Y.J. and F.G.; formal analysis, J.J.; data curation, M.C. and X.L.; writing — original draft preparation, D.T.; writing—review and editing, M.C. and Z.Z.; supervision, R.G. and Z.Z. All authors have read and agreed to the published version of the manuscript.

Funding: This research was funded by National Natural Science Foundation of China, grant numbers 51974083 and U1764254, and the Fundamental Research Funds for the Central Universities, grant number N2002016.

Acknowledgments: Special thanks are due to the instrumental analysis from Analytical and Testing Center, Northeastern University.

Conflicts of Interest: The authors declare no conflict of interest.

\section{References}

1. Song, J.F.; She, J.; Chen, D.L.; Pan, F.S. Latest research advances on magnesium and magnesium alloys worldwide. J. Magnes. Alloys 2020, 8, 1-41. [CrossRef]

2. Wang, W.; Han, P.; Peng, P.; Zhang, T.; Liu, Q.; Yuan, S.N.; Huang, L.Y.; Yu, H.L.; Qiao, K.; Wang, K.S. Friction Stir Processing of Magnesium Alloys: A Review. Acta Metall. Sin. Engl. Lett. 2020, 33, 43-57. [CrossRef]

3. Peng, Q.; Sun, Y.; Ge, B.; Fu, H.; Zu, Q.; Tang, X.; Huang, J. Interactive contraction nanotwins-stacking faults strengthening mechanism of Mg alloys. ACTA Mater. 2019, 169, 36-44. [CrossRef]

4. Hirsch, J.; Al-Samman, T. Superior light metals by texture engineering: Optimized aluminum and magnesium alloys for automotive applications. ACTA Mater. 2013, 61, 818-843. [CrossRef]

5. Liu, J.N.; Bian, D.; Zheng, Y.F.; Chu, X.; Lin, Y.L.; Wang, M.; Lin, Z.; Li, M.F.; Zhang, Y.; Guan, S.K. Comparative in vitro study on binary Mg-RE (Sc, Y, La, Ce, Pr, Nd, Sm, Eu, Gd, Tb, Dy, Ho, Er, Tm, Yb and Lu) alloy systems. Acta Biomater. 2020, 102, 508-528. [CrossRef]

6. Chang, C.I.; Du, X.H.; Huang, J.C. Achieving ultrafine grain size in Mg-Al-Zn alloy by friction stir processing. Scr. Mater. 2007, 57, 209-212. [CrossRef]

7. Azzeddine, H.; Hanna, A.; Dakhouche, A.; Rabahi, L.; Scharnagl, N.; Dopita, M.; Brisset, F.; Helbert, A.L.; Baudin, T. Impact of rare-earth elements on the corrosion performance of binary magnesium alloys. J. Alloys Compd. 2020, 829, 14. [CrossRef]

8. Lin, H.; Yang, M.; Tang, H.; Pan, F. Effect of minor Sc on the microstructure and mechanical properties of AZ91 Magnesium Alloy. Prog. Nat. Sci. Mater. Int. 2018, 28, 66-73. [CrossRef]

9. Liu, Y.F.; Jia, X.J.; Qiao, X.G.; Xu, S.W.; Zheng, M.Y. Effect of La content on microstructure, thermal conductivity and mechanical properties of Mg-4Al magnesium alloys. J. Alloys Compd. 2019, 806, 71-78. [CrossRef] 
10. Sahoo, B.N.; Panigrahi, S.K. Effect of in-situ (TiC-TiB2) reinforcement on aging and mechanical behavior of AZ91 magnesium matrix composite. Mater. Charact. 2018, 139, 221-232. [CrossRef]

11. Wang, B.; Chen, X.; Pan, F.; Mao, J. Effects of Sn addition on microstructure and mechanical properties of Mg-Zn-Al alloys. Prog. Nat. Sci. Mater. Int. 2017, 27, 695-702. [CrossRef]

12. Tie, D.; Zhang, B.; Yan, L.; Guan, R.; Ji, Z.; Liu, H.; Zhang, D.; Liu, D.; Chen, M. Rheological Solidification Behavior and Mechanical Properties of AZ91-Sn Alloys. Crystals 2019, 9, 641. [CrossRef]

13. Yuan, G.; Sun, Y.; Ding, W. Effects of bismuth and antimony additions on the microstructure and mechanical properties of AZ91 magnesium alloy. Mater. Sci. Eng. A 2001, 308, 38-44.

14. Luo, Q.; Guo, Y.L.; Liu, B.; Feng, Y.J.; Zhang, J.Y.; Li, Q.; Chou, K. Thermodynamics and kinetics of phase transformation in rare earth-magnesium alloys: A critical review. J. Mater. Sci. Technol. 2020, 44, 171-190. [CrossRef]

15. Fu, L.; Le, Q.; Hu, W.; Zhang, J.; Wang, J. Strengths and ductility enhanced by micro-alloying Sm/La/Ca to Mg-0.5Zn-0.2Mn alloy. J. Mater. Res. Technol. 2020, 9, 6834-6849. [CrossRef]

16. Nami, B.; Shabestari, S.G.; Razavi, H.; Mirdamadi, S.; Miresmaeili, S.M. Effect of Ca, RE elements and semi-solid processing on the microstructure and creep properties of AZ91 alloy. Mater. Sci. Eng. A 2011, 528, 1261-1267. [CrossRef]

17. Luo, Q.; Zhai, C.; Gu, Q.F.; Zhu, W.F.; Li, Q. Experimental study and thermodynamic evaluation of Mg-La-Zn system. J. Alloys Compd. 2020, 814, 13. [CrossRef]

18. Wong, C.; Styles, M.J.; Zhu, S.; Qiu, D.; McDonald, S.D.; Zhu, Y.; Gibson, M.A.; Abbott, T.B.; Easton, M.A. (Al, Mg)3La: A new phase in the Mg-Al-La system. ACTA Crystallogr. B 2018, 74, 370-375. [CrossRef]

19. Liu, Y.F.; Qiao, X.G.; Li, Z.T.; Xia, Z.H.; Zheng, M.Y. Effect of nano-precipitation on thermal conductivity and mechanical properties of Mg-2Mn-xLa alloys during hot extrusion. J. Alloys Compd. 2020, 830, 9. [CrossRef]

20. Zhang, B.; Jia, H.C.; Lian, Q.Y.; Jiang, L.Y.; Wu, G.X. Effect of extrusion treatment on mechanical, thermal conductivity and corrosion resistance of magnesium alloys. Mater. Express 2019, 9, 405-412. [CrossRef]

21. Zhang, M.; Li, W.; Zhao, J.; Chen, M.F. Comparative study of the effects of CaO and Ce-La misch metal on the microstructure and properties of AZ91 alloy. J. Mater. Res. Technol. 2020, 9, 5194-5203. [CrossRef]

22. Mokhtarishirazabad, M.; Boutorabi, S.M.A.; Azadi, M.; Nikravan, M. Effect of rare earth elements on high cycle fatigue behavior of AZ91 alloy. Mater. Sci. Eng. A 2013, 587, 179-184. [CrossRef]

23. Jain, V.; Mishra, R.S.; Gupta, A.K.; Gouthama. Study of $\beta$-precipitates and their effect on the directional yield asymmetry of friction stir processed and aged AZ91C alloy. Mater. Sci. Eng. A 2013, 560, 500-509. [CrossRef]

24. Stanford, N.; Geng, J.; Chun, Y.B.; Davies, C.H.J.; Nie, J.F.; Barnett, M.R. Effect of plate-shaped particle distributions on the deformation behaviour of magnesium alloy AZ91 in tension and compression. ACTA Mater. 2012, 60, 218-228. [CrossRef]

25. Meng, F.; Lv, S.; Yang, Q.; Qin, P.; Zhang, J.; Guan, K.; Huang, Y.; Hort, N.; Li, B.; Liu, X.; et al. Developing a die casting magnesium alloy with excellent mechanical performance by controlling intermetallic phase. J. Alloys Compd. 2019, 795, 436-445. [CrossRef]

26. Feng, A.H.; Ma, Z.Y. Microstructural evolution of cast Mg-Al-Zn during friction stir processing and subsequent aging. ACTA Mater. 2009, 57, 4248-4260. [CrossRef]

27. Zhao, C.; Chen, X.; Pan, F.; Gao, S.; Zhao, D.; Liu, X. Effect of Sn content on strain hardening behavior of as-extruded Mg-Sn alloys. Mater. Sci. Eng. A 2018, 713, 244-252. [CrossRef]

28. Zhao, C.; Chen, X.; Pan, F.; Wang, J.; Gao, S.; Tu, T.; Liu, C.; Yao, J.; Atrens, A. Strain hardening of as-extruded Mg-xZn (x = 1, 2, 3 and 4 wt\%) alloys. J. Mater. Sci. Technol. 2019, 35, 142-150. [CrossRef]

29. Song, B.; Wang, C.P.; Guo, N.; Pan, H.C.; Xin, R.L. Improving Tensile and Compressive Properties of an Extruded AZ91 Rod by the Combined Use of Torsion Deformation and Aging Treatment. Materials 2017, 10, 13. [CrossRef]

30. Bu, F.; Yang, Q.; Guan, K.; Qiu, X.; Zhang, D.; Sun, W.; Zheng, T.; Cui, X.; Sun, S.; Tang, Z.; et al. Study on the mutual effect of $\mathrm{La}$ and $\mathrm{Gd}$ on microstructure and mechanical properties of $\mathrm{Mg}-\mathrm{Al}-\mathrm{Zn}$ extruded alloy. J. Alloys Compd. 2016, 688, 1241-1250. [CrossRef]

31. Li, B.; Ma, Q.; McClelland, Z.; Horstemeyer, S.J.; Whittington, W.R.; Brauer, S.; Allison, P.G. Twin-like domains and fracture in deformed magnesium. Scr. Mater. 2013, 69, 493-496. [CrossRef]

32. Li, K.; Injeti, V.S.Y.; Misra, R.D.K.; Meng, L.G.; Zhang, X.G. The contribution of long-period stacking-ordered structure (LPSO) to high strength-high ductility combination and nanoscale deformation behavior of magnesium-rare earth alloy. Mater. Sci. Eng. A 2018, 713, 112-117. [CrossRef] 
33. Teschke, M.; Koch, A.; Walther, F. Comparison of High-Temperature Compression and Compression-Compression Fatigue Behavior of Magnesium Alloys DieMag422 and AE42. Materials 2020, 13, 15. [CrossRef]

34. Mulay, R.P.; Agnew, S.R. The fracture behavior of B2 structured MgR intermetallics. Scr. Mater. 2009, 61, 1036-1039. [CrossRef]

35. Orlov, D.; Raab, G.; Lamark, T.T.; Popov, M.; Estrin, Y. Improvement of mechanical properties of magnesium alloy ZK60 by integrated extrusion and equal channel angular pressing. ACTA Mater. 2011, 59, 375-385. [CrossRef]

(c)

(C) 2020 by the authors. Licensee MDPI, Basel, Switzerland. This article is an open access article distributed under the terms and conditions of the Creative Commons Attribution (CC BY) license (http://creativecommons.org/licenses/by/4.0/). 